The World Health Organization (WHO) (2003) recommends that everyone with mental health problems induced by trauma and loss, ranging from preexisting severe mental disorder to non-pathological psychological distress, should have access to basic mental healthcare from general health services and community mental health services. The $\mathrm{WHO}$ has advised countries to make social and basic psychological interventions available to the whole population in the community through a variety of sectors, including the health sector. These interventions may also provide some support to those people with mental disorders who do not seek help within the health sector. Such intervention could include restarting schooling, organising child-friendly spaces, family reunification programmes and economic development initiatives (Van Ommeren et al, 2005).

In the limited time available, the main objective of our team was to give as much help as possible to the affected population. This was achieved by providing clinical services at various peripheral settings. Training programmes for the doctors and the paramedical professionals were conducted to prepare them to provide help to the affected population.

It was not possible to collaborate with the local mental health professionals during the team's visit, as the area had also been affected by terrorism and the team was advised to be back to their bases by 6 p.m.
Future plan

It would be good to reassess the situation after 6-9 months and to identify the mental health needs of the population at that time, to inform service provision. It would be advisable to include the local mental health professionals in planning such work.

\section{References}

de Jong, J. T. V. M., Komproe, I. H. \& Van Ommeren, M. (2003) Common mental disorders in postconflict settings. Lancet, 36I, 2128-2130

Goel, D. S., Agarwal, S. P., Ichhpujani, R. L., et al (2004) Mental health 2003: Indian scene. In Mental Health: An Indian Perspective 1946-2003 (ed. S. P. Agarwal). New Delhi: Directorate General of Health Services, Ministry of Health and Family Welfare.

Jones, L., Rrustemi, A., Shahini, M., et al (2003) Mental health services for war-affected children: report of a survey in Kosovo. British Journal of Psychiatry, 183, 540-546.

Makhdum, M. A. \& Javed, A. (2005) Earthquake in Pakistan and Kashmir: suggested plan for psychological trauma relief work. International Psychiatry, 3, 16-18.

Silove, D., Manicavasagar, V., Baker, K., et al (2004) Indices of social risk among first attenders of an emergency mental health service in post-conflict East Timor: an exploratory investigation. Australian and New Zealand Journal of Psychiatry, 38, 929-932.

Van Ommeren, M., Saxena, S. \& Saraceno, B. (2005) Aid after disasters. Editorial. BM/, 330, ||60-1|61.

World Health Organization (2003) Mental Health in Emergencies: Psychological and Social Aspects of Health of Populations Exposed to Extreme Stressors. Geneva: WHO.
The authors are grateful to the

Director of Health

Services, Kashmir

(India) and the

Principal, Regional

Institute of Health

and Family Welfare,

Dhobiwan (J\&K),

for providing the

help and support

during the team's

work in the state.

The authors are also grateful to all other

members of the

team (Dr N. Kaw,

Dr J. Singh, Braham

Prakash, Deepak

Yadav, Davinder

Rana, Pritpal Singh

and Om Prakash

Giri) for their hard work.

\title{
Ten months on: qualitative assessment of psychosocial issues in northern Sri Lanka following the tsunami
}

\author{
K. Danvers' ${ }^{1}$ S. Sivayokan², \\ D. J. Somasundaram ${ }^{3}$ and R. Sivashankar ${ }^{4}$ \\ ${ }^{1}$ Clinical Psychologist, 'Shanthiham', Association For Health and Counselling, 8/1 Kapakavinayar Lane, Kachcheri \\ Nallur Road, Jaffna, Sri Lanka, email kate_danvers@yahoo.co.uk \\ ${ }^{2}$ Acting Consultant Psychiatrist, Psychiatry Unit, Teaching Hospital Jaffna, Hospital Road, Jaffna, Sri Lanka \\ ${ }^{3}$ Professor of Psychiatry, Faculty of Medicine, University of Jaffna, Jaffna, Sri Lanka \\ ${ }^{4}$ Medical Officer, Blood Bank, Teaching Hospital Jaffna, Hospital Road, Jaffna, Sri Lanka
}

he tsunami which affected South Asia on 26

December 2004 caused over 4I 000 deaths in Sri Lanka, representing $0.2 \%$ of the total population, and displaced over 880000 people from their homes and livelihoods (World Health Organization, 2004). Kilinochchi, Jaffna and Mullativu districts in the Northern Province of Sri Lanka were affected by the tsunami and, as of April 2005, in the whole province, 6200 people had lost their lives, 961 were still missing, 19618 were still housed in welfare centres and 45548 were housed with relatives and friends (Government of Sri Lanka, 2005).
The Northern Province of Sri Lanka is populated predominantly by Tamils and has experienced many years of civil war. There is currently a ceasefire, but because of the war many people in the north had experienced trauma and displacement before the tsunami. Although government mental health services in the province are chronically underfunded, over the years these have been supplemented by the development of local non-governmental organisations (NGOs) with expertise in community psychosocial interventions aimed at targeting the effects of war, particularly its post-traumatic effects. On 29 December
Dr Danvers'

association with

Shanthiham is through Voluntary

Service Overseas, 317 Putney Bridge

Road, London

SW15 2PN, UK 
2004 many of the agencies based in the Jaffna District came together to form the Mental Health Task Force in Disaster, with the aim of coordinating psychosocial aid after the tsunami.

\section{Qualitative assessment of psychosocial issues 3 months after the tsunami}

The scale of the loss was immense: many members of single families were killed and in some communities all families lost relatives or close friends. Deaths were often very traumatic and were witnessed by the surviving relative.

\section{After the tsunami \\ there was an \\ increase in relapse of schizophrenia, exacerbation of symptoms and failure to follow regular treatment routines.}

As psychiatrists working directly with people affected by the tsunami, and as supervisors of the counsellors and psychosocial workers who were visiting the welfare centres, we made the following observations about the impact of the tsunami.

The scale of the loss was immense: many members of single families were killed and in some communities all families lost relatives or close friends. Deaths were often very traumatic and were witnessed by the surviving relative. For example, there were many reports of mothers having young children pulled from their arms by the force of the water. Those who did not lose family members often experienced property and financial loss. Shortly after the disaster, many had to search for family members, as surviving relatives were often separated, staying in different welfare centres, for instance. There was less opportunity to carry out traditional funeral rituals and in many cases bodies were never recovered. Village structures and organisations were destroyed, and there was large-scale displacement. Because of these factors, the usual community support available after bereavement was not available, since all in the affected communities were dealing with their own losses.

Immediately after the tsunami, many people experienced an acute stress reaction - feeling dazed and highly emotional; this typically lasted a few days. Unsurprisingly, grief was the predominant psychological symptom. Factors which complicated grief reactions included the following:

O Guilty feelings. Commonly, survivors questioned themselves about what they could have done differently to save physically weaker family members.

o Anger and hostility. These were directed towards nature or the gods, at family members (e.g. parents blaming each other for the deaths of children), or at outside agencies, such as the government or staff in welfare centres.

o Missing people. In cases where no body was recovered, unanswered questions and ongoing hopes of survival were common.

o Suicidal ideation. Guilt was a risk factor for suicidal ideation, as was losing a large proportion of close family. There was one case of suicide due to property loss in the first few weeks.

o Alcohol misuse. This was especially common in men who had lost their wives and were struggling to cope with young children.

Fear of the sea and nightmares were initially common, as were fears relating to the future and a return to coastal areas. Most of the affected areas were fishing communities, and mistrust of nature was expressed as 'She who gave everything also destroyed everything'. Vivo, a psychosocial NGO working in Sri Lanka, carried out a brief survey of 71 children (aged 8-15) 3-4 weeks after the tsunami. The survey showed that $40 \%$ were at risk of developing posttraumatic stress disorder (PTSD) and many others showed symptoms. There were rumours relating to the cause of the tsunami and reports of another tsunami coming were initially common. Some people developed magical thinking about the disaster or about ways to keep safe.

There is an elevated incidence of schizophrenia in the Jaffna Tamil community compared with other East Asian communities (Somasundaram et al, 1988). After the tsunami there was an increase in relapse of schizophrenia, exacerbation of symptoms and failure to follow regular treatment routines. Some individuals lost their medical records and medications, and defaulted clinic appointments and treatments. Some cases of schizophrenic illness or other psychotic episodes were not identified, or were misidentified as normal reactions to the disaster, and were managed only with psychological methods.

Jaffna town, where government offices and most of the NGOs are based, was not affected by the tsunami. In the first 2 weeks after the tsunami, in the town there was a sense of excitement and arousal which at times seemed to border on mass hysteria. Many of those providing practical or psychosocial help to the affected people expressed satisfaction (and some even elation) at being able to help and in the community there was a general wish to visit the tsunami-affected areas, even when this was not strictly necessary. We were surprised by the number of volunteers wanting to carry out psychosocial activities, and were concerned that some went to the affected communities offering 'counselling' despite not having any psychosocial skills or training. We were also concerned about the psychological effect of this desire to help, on both the tsunami-affected people and the volunteers, and were aware of some volunteers who experienced severe and acute stress reactions in response to traumatic experiences such as witnessing the aftermath of the tsunami or disposing of dead bodies.

Some aspects of the systems put in place after the tsunami to deliver aid seemed to lead to more difficulties for the affected people. There was a complex official registration process for receiving aid, which many found stressful. Initially agencies were poorly organised and coordinated, and there were some cases of political interference in the supply of aid and provision of psychosocial support. Many felt this led to aid and psychosocial interventions not reaching all those in need, which caused resentment and anger among the affected people. Initially, few structured activities were available in the welfare centres, and this particularly affected children and adolescents who had 
lost parents. As time went on, there were reports of a lack of sensitivity and sympathy on the part of some authorities dealing with tsunami survivors, including school principals and government officers.

\section{Psychosocial interventions in the 3 months after the tsunami}

Research suggests that, for most people, psychological reactions resolve during the first or second month after a disaster. Early, in-depth psychological interventions that force the client to talk about experiences in detail can prove harmful to some (Rose et al, 2002), so the Task Force advocated avoiding this approach. Instead, we disseminated information about normal psychological reactions, with an emphasis on the expectation of natural recovery (World Heath Organization, 2003), while also ensuring that a system for psychiatric referral was in place for the minority with more severe or abnormal psychological reactions.

Counsellors and psychosocial workers from Jaffna NGOs were sent to the welfare centres to offer support and information. All were given a training session focusing on how they could adapt their skills to the immediate post-disaster context and the dangers of compulsory debriefing sessions. They were also given information on how to identify and refer individuals at risk of harm. Primary healthcare workers (e.g. public health inspectors and midwives) were given a similar training programme and asked to look into psychosocial issues as well as their normal work.

The Task Force coordinated articles in the local papers, gave interviews and a press conference, and also produced information leaflets for affected people and aid workers. Through contacts with the media we hoped to encourage social agencies to promote normality and resettlement as soon as possible, and to influence newspapers' reporting style to avoid increased public distress.

The Task Force attended coordination meetings of the various government agencies and NGOs in order to highlight and advocate psychosocial issues and contribute to planning.

\section{Reflections 10 months on}

Saraceno \& Minas (2005) estimate that, of those directly affected by disaster, 50\% will have psychosocial problems needing help and support and 5-10\% will develop severe problems (e.g. pathological grief, PTSD and depression) needing specific intervention and treatment. In our area, pathological grief, phobias, depression and PTSD were the most common psychiatric disorders emerging after the tsunami. To date, in the Jaffna district, we have not experienced the expected large rise in numbers of people directly seeking psychiatric support as a result of the tsunami. Many of those we have seen have been referred from other medical units, such as out-patient departments, with somatisation. Quite a number may be in the community with unrecognised psychiatric problems. When special efforts were made to identify people with psychological problems, large numbers were found. For example, in a badly affected coastal area, Maruthenkerny, regular psychiatric clinics found almost half of those attending had a post-tsunami psychiatric disorder, particularly PTSD and depression.

Against our initial expectations, there was a high level of interest within the national and international community in the possible psychological effect of the tsunami and, hence, funds were easily available for psychosocial interventions. In the Jaffna district there were already many NGOs specialising in trauma and psychosocial interventions, so our district was perhaps better prepared than other tsunami-affected areas to mobilise resources quickly. However, in areas of the north less well provided with such NGOs, occasional psychiatric field trips have identified many people with depression who have not been referred to appropriate services.

Some felt that because the whole population of Jaffna has previous experience of being displaced (as a result of conflict), our area was better prepared to support those affected. Local people said they know first-hand that when you are displaced you need not only donations of rice but also donations of a pot to cook it in, water to boil and fuel for the fire. Previous traumatic experiences due to war may also have made the population more resilient. Local traditional healers and religious communities already had experience of helping people who have suffered traumatic experiences. The combined effects of resilience resulting from previous trauma and quickly mobilised community psychosocial programmes may have prevented some from developing problems needing referral to hospital-level psychiatric services. However, some people may have suffered without appropriate psychiatric support, because of a perception that they should be resilient and not seek help, or because they mislabelled their symptoms as 'normal'.

The widespread availability of community psychosocial support may also have prevented some from accessing appropriate psychiatric support for their mental health problems. We had concerns that some organisations offering to provide psychosocial support had insufficiently trained staff, who may have struggled to identify mental health problems. People themselves may not be aware that they have problems that could be helped by psychiatric services. In response to these concerns, the Task Force continues to offer education on how to identify people with severe difficulties, and where to refer for appropriate help, as well as awareness-raising sessions in the community.

Despite the amount of time that has passed since the tsunami, very little rebuilding has begun in the north, and many people are still displaced. Political concerns have led to a block in the distribution of aid, resulting in many projects being delayed. There is a perceived unfairness in the aid system, as those who are most affected struggle to access the support
Research suggests that, for most people, psychological reactions resolve during the first or second month after a disaster. Early, in-depth psychological

interventions that force the client

to talk about experiences in detail can prove harmful to some.

To date, in the Jaffna district,

we have not experienced the expected large rise in numbers of people directly seeking psychiatric support as a result of the tsunami. 
Looking to the

future, we may

yet see more

psychiatric

disorders

emerging as

a result of the

tsunami. available. This situation increases the suffering of the affected people and could mean fewer people with psychiatric problems present to the psychiatric service, as they are preoccupied with the day-to-day practical issues of re-establishing their homes and livelihoods.

Since the tsunami, some services (particularly community-based programmes) have been diverted to the tsunami-affected areas, and away from areas which have a high level of psychosocial need as a result of other factors, including poverty and conflict.

Looking to the future, we may yet see more psychiatric disorders emerging as a result of the tsunami, causing increased demand on already overstretched services, but the needs of those affected by the tsunami must be balanced and integrated with those of the rest of the population. The past year has seen unprecedented attention given to mental health by the Sri Lankan government, media and public. We hope this will provide an opportunity for Sri Lanka to reinforce and restructure mental health services for the benefit of the whole population.

\section{References}

Government of Sri Lanka (2005) Tsunami Disaster Figures as of 5th April 2005. Emergency Operation Room of the National Disaster Management Centre. Colombo: Ministry of Women's Empowerment and Social Welfare, Government of Sri Lanka.

Rose, S., Bisson, J. \& Wessely, S. (2002) Psychological debriefing for preventing post traumatic stress disorder (PTSD). Cochrane Database of Systematic Reviews, issue 2. Oxford: Update Software.

Saraceno, B. \& Minas, H. (2005) Mental Health Situation in Aceh. Geneva: WHO. Available at http://www.who.int/mental_health/ resources/Summary\%20Indonesia\%20Strategic\%20plan\%20 revised\%2027\%20Jan.pdf. Last accessed 20 April 2006.

Somasundaram, D. J., Yoganathan, S. \& Ganesvaran, T. (1988) Schizophrenia in Sri Lankan Tamils - a descriptive study. Ceylon Medical Journal, 38, I31-135.

World Health Organization (2003) Mental Health in Emergencies. Geneva: WHO.

World Health Organization (2004) Situational Reports on South-East Asia Earthquake and Tsunami. Available at http://w3.whosea. org/en/Section23/Section I 108/Section 1835_8139.htm. Last accessed 20 April 2006.

\section{Different disasters, different needs}

\section{Diyanath Samarasinghe}

Professor of Psychiatry, Faculty of Medicine, Kynsey Road, Colombo 8, Sri Lanka, email dsamara@vinet.lk

\section{With the tsunami}

... numerous

families lost

more than one

member. Indeed,

in some instances, not altogether

rare, just a single member survived.

The needs of such special survivors are not addressed adequately in the usual responses to disasters.
$\mathrm{D}$ ifferent kinds of disaster create dissimilar conditions for survivors, and the specific realities associated with each must guide our helping responses. This in no way negates the importance of having general principles to follow in responding to major disasters (Sphere Project, 2004; van Ommeren et al, 2005).

For instance, many of the families who lost one or more members in the tsunami that hit Sri Lanka in December 2004 also lost their homes, the rest of the community infrastructure and virtually all their belongings, but they lived alongside others similarly affected. Their experiences are of a different kind altogether from, for example, those who lost loved ones in the terrorist attacks in the United States on II September 200I - many of whom were geographically distant and for whom the physical infrastructure was mostly intact (Roxane et al, 2002; Simeon et al, 2003). Reactions against the presumed perpetrator, too, are of contrasting kinds in the two examples. Extreme anger and hostility are commonplace in disasters engineered by humans but virtually impermissible when the disaster is classed as an 'act of God'. These and other factors lead to major differences in what happens, and what we need to do, after any particular disaster.
I set out below some developments following the tsunami-related havoc in Sri Lanka which point to specific needs associated with disasters of this kind.

\section{Direct destruction affected whole families and communities}

Some disasters claim individual victims from any one family or social network. An example would be a terrorist bomb blast on a tube train, as happened in London in July 2005. Each bereaved family then usually has to respond to the loss of a single relative. With the tsunami, in contrast, numerous families lost more than one member. Indeed, in some instances, not altogether rare, just a single member survived. The needs of such special survivors are not addressed adequately in the usual responses to disasters. Their psychological needs are generally a later consideration in our formal planned responses.

There is perhaps a need to question the widespread acceptance of the benefits of medications and psychological intervention to facilitate emotional ventilation and cognitive adjustment among those affected by severe trauma (de Vries, 1998; Pupavac, 